\title{
Usefulness of transcutaneous Doppler jugular venous echo to predict pulmonary hypertension in COPD patients
}

\author{
W. Matsuyama*, R. Ohkubo*, K. Michizono*, M. Abe*, Y. Nakamura\# ${ }^{\#}$ M. Kawabata*, M. Osame*
}

Usefulness of transcutaneous Doppler jugular venous echo to predict pulmonary hypertension in COPD patients. W. Matsuyama, R. Ohkubo, K. Michizono, M. Abe, Y. Nakamura, M. Kawabata, M. Osame. C ERS Journals Ltd 2001.

ABSTRACT: Pulmonary hypertension is an important factor that determines the prognosis of chronic obstructive pulmonary disease (COPD) patients. Echocardiography is a noninvasive and useful bedside method for measurement of pulmonary artery pressure. However, this method is sometimes difficult because of the overinflated lungs in COPD patients. This study attempted to estimate pulmonary hypertension in COPD patients using transcutaneous Doppler jugular vein flow velocity recording.

The mean pulmonary artery pressure (MPAP) of 64 COPD patients was examined using cardiac catheterization. The right jugular vein flow velocity was measured within $24 \mathrm{~h}$ using transcutaneous Doppler echo, after which the ratio of diastolic flow (Df) and systemic flow (Sf) velocity was calculated. Subsequently, the statistical correlation of MPAP and the Df/Sf ratio was examined. MPAP was also measured using standard cardiac echo methods and the results were compared.

The Df/Sf velocity ratio showed significant correlation with MPAP in COPD patients $(r=0.844, p<0.0001)$. The sensitivity was $71.4 \%$, and the specificity $95.3 \%$ (cut-off ratio $=1.0)$. Jugular venous Doppler echo could be performed in all patients while other cardiac echo methods could not be performed in all patients. The specificity of the methods used was higher than other cardiac echo methods.

Transcutaneous jugular vein flow velocity measurement may be applicable to bedside prediction of pulmonary hypertension in chronic obstructive pulmonary disease patients. Eur Respir J 2001; 17: 1128-1131.
*Third Dept of Internal Medicine, Kagoshima University School of Medicine, Sakuragaoka and \# Dept of Cardiology, Nakamura-Onsen Hospital, Ei-cho Beppu 1, Ibusuki-gun, Kagoshima, Japan

Correspondence: W. Matsuyama Third Dept of Internal Medicine Kagoshima University School of Medicine

Sakuragaoka 8-35-1

Kagoshima City 890-8520

Japan

Fax: 81992657164

Keywords: Bedside prediction echocardiography

pulse wave Doppler echo

Received: October 102000

Accepted after revision January 18 2001
Pulmonary hypertension is a frequent complication of the progression of chronic obstructive pulmonary disease (COPD) and is known to indicate a poor prognosis [1]. There are various methods to evaluate pulmonary artery pressure, such as right-sided cardiac catheterization [2], echocardiography [3, 4], electrocardiography [5] and myocardial scintigraphy [6, 7]. However, these methods have some disadvantages, namely: 1) right-sided cardiac catheterization is invasive; 2) echocardiography is sometimes difficult in COPD patients because of the overinflated lungs; 3 ) the specificity and sensitivity of electrocardiography is low [8]; and 4) myocardial scintigraphy is expensive. In 1989, RANGANATHAN and SIVACIYAN [9] reported the usefulness of transcutaneous Doppler jugular venous flow velocity recording to estimate pulmonary artery pressure in patients with cardiac disorders but this method was not investigated in COPD patients. This study measured mean pulmonary artery pressure (MPAP) in COPD patients using the previous methods and investigated the predicted value of transcutaneous Doppler jugular venous flow velocity recording. This method was found to be applicable for bedside prediction of pulmonary hypertension in COPD patients.

\section{Patients and methods}

This study investigated 64 COPD patients $(60$ males) who were admitted to the Third Dept of Internal Medicine (Kagoshima University School of Medicine) and the Dept of Cardiology (NakamuraOnsen Hospital). Fifty-nine patients were suffering from emphysema while others had chronic bronchitis. All patients gave their written consent to participate in this study. All patients with tachycardia, arrythmia, infectious disorders, malignant tumour, head and neck abnormalities, ischaemic heart disease and cardiac disorders which cause pulmonary hypertension (e.g. tricuspid valve disorder, left ventricular dysfunction) were excluded. The MPAPs of all patients were measured using the cardiac catheterization method [2] by cardiology specialists. MPAP was measured three times at the end of the expiratory phase with breath holding and the average was calculated. The patients with mean pulmonary artery pressures of $>25 \mathrm{mmHg}$ were defined as having pulmonary hypertension. For all patients, jugular venous flow velocity recordings were performed prior to the catheter method. After careful examination of the right jugular venous pulse contour with special 
attention to the systolic and diastolic descents, right jugular vein flow velocity was measured using Aloka, ProSound 5000 (7.5 MHz; Tokyo, Japan) at the end of the expiratory phase with breath holding. Variations in the jugular vein velocity pattern were identified by determining the following as previously reported [9]: 1) monophasic or biphasic flow; 2) systolic flow (Sf) or diastolic flow (Df); 3) if flow is biphasic, the ratio of the velocities (Df/Sf velocity) was calculated; 4) direction of flow (antegrade or retrograde); and 5) if retrograde, whether flow occurred during systole or end-diastole. At the same time, the diameter of the inferior vena cava at the expiratory phase was measured and two standard cardiac echo methods that estimate pulmonary hypertension measured: 1) the ratio of acceleration time (AT) and ejection time (ET) (AT/ET) in the pulmonary out flow using pulsed Doppler echo (method A) [3]; and 2) echo Doppler estimation of tricuspid regurgitant wave velocity (method B) [4]. In all procedures, the Doppler investigators were blinded to the catheter results.

\section{Statistical analysis}

This study examined the statistical associations of MPAP and jugular vein flow velocity or diameter of the inferior vena cava. Pearson's correlation coefficient was used to examine the statistical correlations between these parameters. The results from the primary method used in this study and two standard cardiac echo methods were compared. A p-value $<0.05$ was considered significant.

\section{Results}

Twenty-one patients were diagnosed with pulmonary hypertension and the clinical data of all patients are shown in table 1. A reliable echo window was obtained from 56 patients $(87.5 \%)$ using method A and from 35 patients $(54.7 \%)$ using method B, while all patients were applicable for transcutaneous jugular Doppler venous echo. The diameter of the inferior vena cava could be measured in $84.4 \%(54 / 64)$ patients. Regarding jugular venous flow velocity, all patients showed a biphasic pattern without any retrograde flow. The patients with normal MPAP showed a biphasic pattern, and the Sf velocity was

Table 1. - Clinical data of the patients in this study

\begin{tabular}{lccc}
\hline & With PH & Without PH & p-value \\
\hline Subjects n & 21 & 43 & \\
Age yrs & $64.3 \pm 15.8$ & $66.3 \pm 16.1$ & $\mathrm{NS}$ \\
FEV1 \% pred & $45.3 \pm 12.3$ & $60.1 \pm 18.9$ & 0.001 \\
VC \% pred & $67.1 \pm 10.2$ & $78.2 \pm 17.3$ & 0.01 \\
$P \mathrm{a}, \mathrm{O}_{2} \mathrm{mmHg}$ & $61.6 \pm 10.1$ & $77.5 \pm 19.9$ & 0.01 \\
$\mathrm{~Pa}_{\mathrm{a}} \mathrm{CO}_{2} \mathrm{mmHg}$ & $48.1 \pm 14.1$ & $43.2 \pm 17.1$ & 0.01 \\
\hline
\end{tabular}

PH: pulmonary hypertension; FEV1: forced expiratory volume in one second; $\mathrm{VC}$ : vital capacity; $\mathrm{Pa}_{\mathrm{a}} \mathrm{O}_{2}$ : arterial oxygen partial pressure; $P \mathrm{a}, \mathrm{CO}_{2}$ : arterial carbon dioxide partial pressure. greater than the Df velocity (fig. 1a). Conversely, in the patient with pulmonary hypertension, the Sf velocity was almost equal or lower than the Df velocity (fig. 1b, c). The ratio of Df/Sf velocity showed a significantly strong positive correlation with MPAP $(\mathrm{r}=0.844, \mathrm{p}<0.0001$, fig. $2 \mathrm{a})$, but the statistical correlation of the diameter of inferior vena cava with MPAP was not so strong $(\mathrm{r}=0.35, \mathrm{p}=0.014)$. This ratio was almost even (Df velocity was almost equal to $\mathrm{Sf}$ velocity) in the patients with mild pulmonary hypertension $(25-35 \mathrm{mmHg})$, but more than one (Df velocity $>$ Sf velocity) in the patients with severe pulmonary hypertension $(>35 \mathrm{mmHg})$. The sensitivity of this ratio was $71.4 \%$ and the specificity
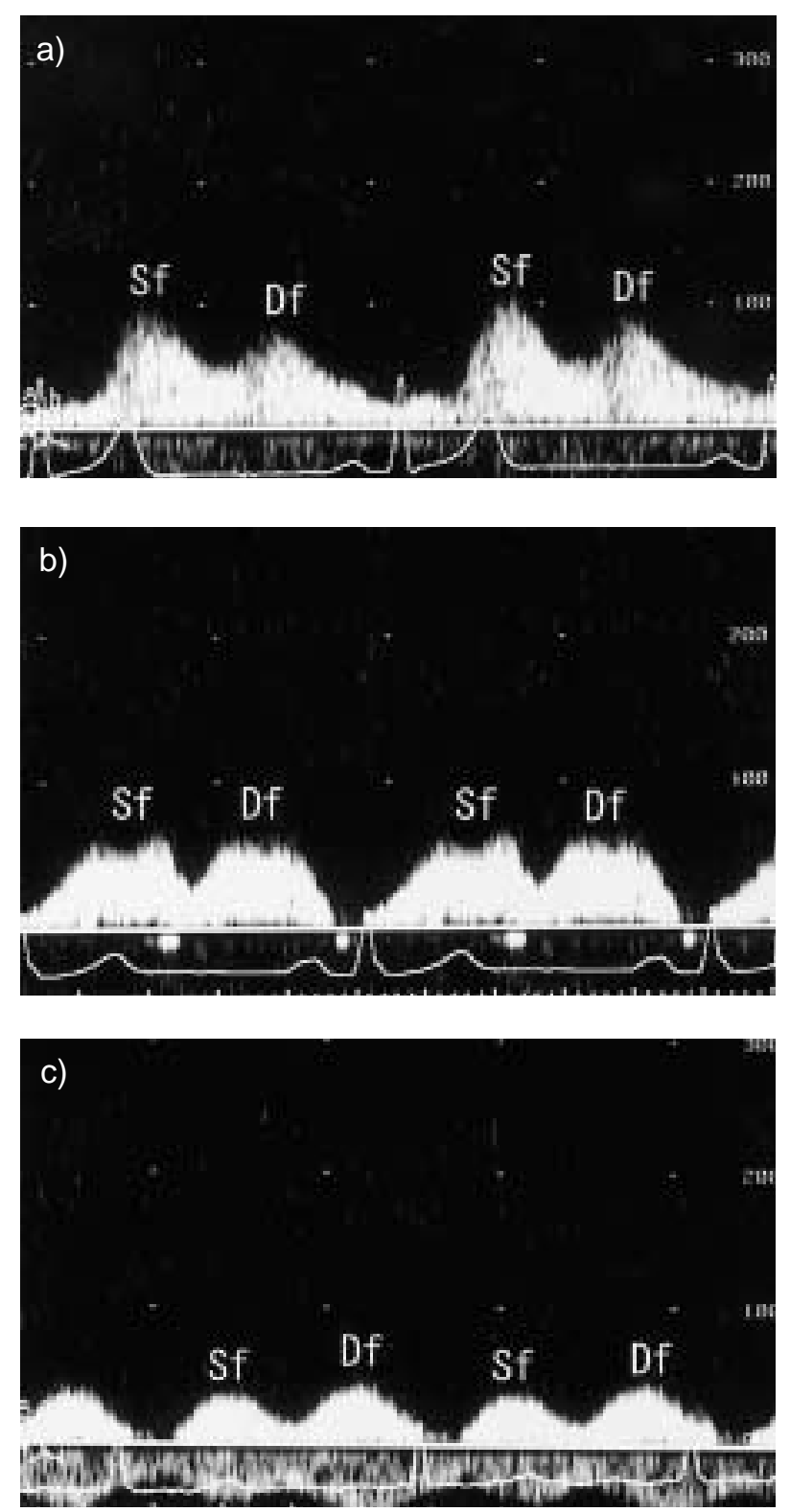

Fig. 1. - Examples of jugular venous flow velocity. a) patient with normal pulmonary artery pressure ( $\mathrm{Df}<\mathrm{Sf}$ velocity); b) patient with mild pulmonary hypertension (Df almost equal to Sf velocity); and c) patient with severe pulmonary hypertension (Df $>$ Sf velocity). 

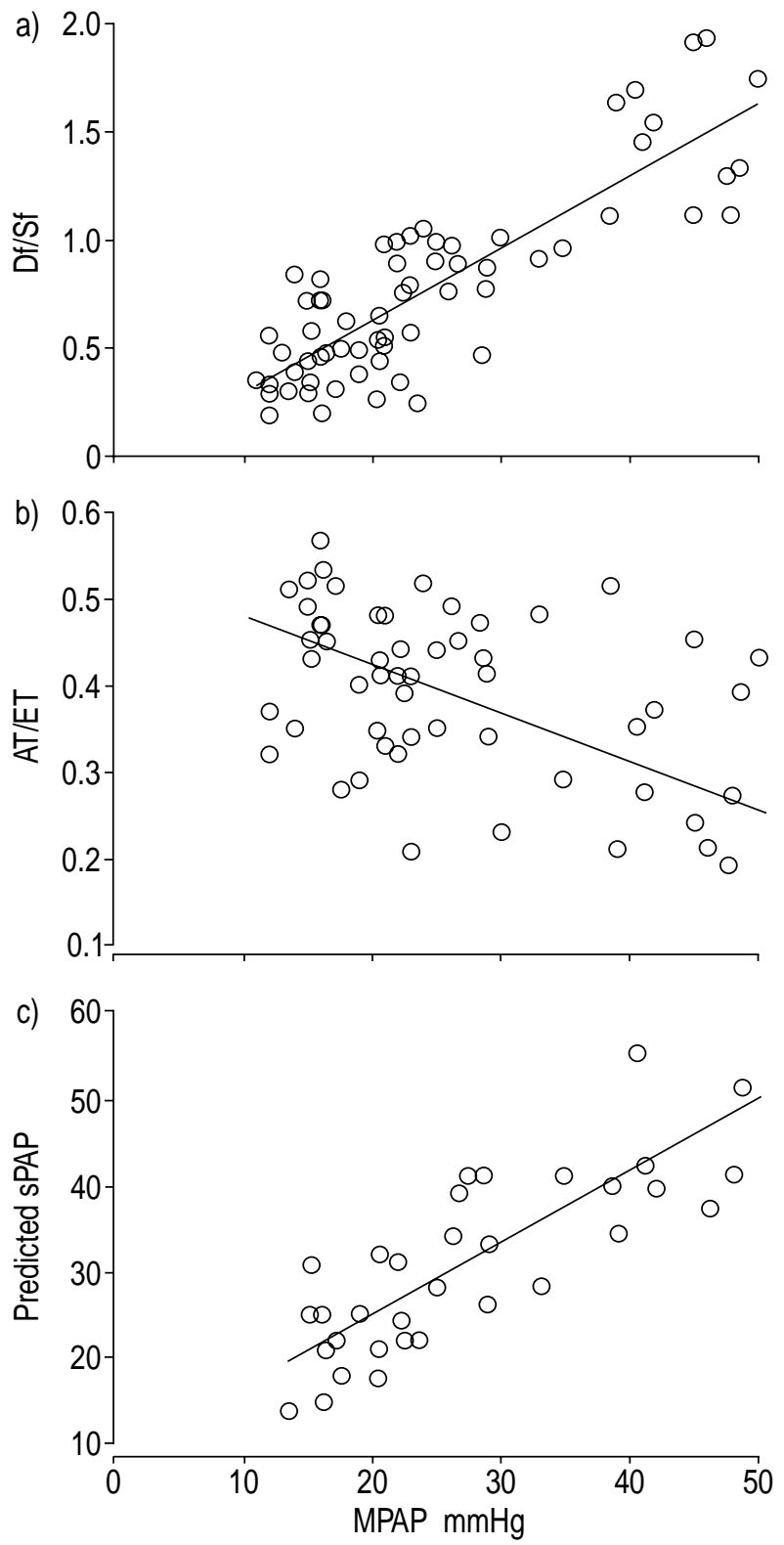

Fig. 2. - Comparison of three noninvasive echo methods. a) Diastolic flow (Df)/systolic flow (Sf) versus mean pulmonary artery pressure (MPAP); b) acceleration time (AT)/ejection time (ET) in the pulmonary out flow versus MPAP $(\mathrm{n}=54)$; c) predicted systolic pulmonary artery pressure (sPAP) using echo doppler estimation of tricuspid regurgitant wave velocity versus $\operatorname{MPAP}(\mathrm{n}=35)$. All methods showed significant correlation with MPAP. The method using Df/Sf was successfully performed in all patients while other methods could not be performed in all.

95.3\% (cut-off ratio $=1.0$ ). Regarding other echocardiographic methods, the ratio of AT/ET in method A showed a significant negative correlation with MPAP $(\mathrm{r}=-0.602, \mathrm{p}<0.01$, fig $2 \mathrm{~b})$, and the sensitivity and specificity were $83.3 \%$ and $85.1 \%$, respectively (cut-off ratio $=0.4$ ). In method $B$, predicted systolic pulmonary artery pressure showed a significant positive correlation with MPAP $(\mathrm{r}=0.826, \mathrm{p}<0.0001$, fig. $2 \mathrm{c})$, and the sensitivity was $82.9 \%$ and the specificity was $86.1 \%$ (cut-off systolic pulmonary artery pressure $=$ $40 \mathrm{mmHg}$ ).

\section{Discussion}

Pulmonary hypertension frequently results in cor pulmonale and symptomatic congestive heart failure $[1,10]$. There are some noninvasive bedside methods to estimate pulmonary artery pressure using cardiac echo [3, 4, 11], but these methods are sometimes difficult in COPD patients because of their overinflated lungs [8]. In fact, reliable echo windows were not obtained for all COPD patients. RANGANATHAN and SivaciYan [9] reported the usefulness of jugular venous flow velocity recording for estimation of pulmonary hypertension in patients with cardiac disorders. Further, they indicated a clinical and haemodynamic correlation with jugular venous flow and emphasized the applicability to bedside evaluation of patients with pulmonary hypertension in cardiac disorders [12]. In the present study, the diameter of the inferior vena cava, one of the parameters of pulmonary hypertension, did not show a significant statistical correlation with pulmonary artery pressure unlike the ratio of $\mathrm{Df} / \mathrm{Sf}$ velocity. The diameter of the inferior vena cava could be measured in $84.4 \%$ of patients, as previously reported [13]. Furthermore, jugular venous Doppler echo was successfully performed in all patients, while other cardiac echo methods could not be performed in all patients and the specificity of this ratio was fairly high $(95.3 \%)$ compared with other cardiac echo methods. The authors suggest that jugular venous flow velocity recording is applicable for the bedside estimation of pulmonary hypertension in COPD patients.

The patients with pulmonary hypertension showed an increase in the ratio of Df/Sf velocity. The jugular venous flow velocity is known to peak twice; once immediately in systole and once during diastole [9]. The systolic forward flow is initiated by atrial relaxation ( $\mathrm{X}$ descent) $[14,15]$ but is mainly determined by the descent of the base ( $\mathrm{X}^{\prime}$ descent) during ventricular systole, when tracing the ventricle [16-18]. This decrease in atrial pressure produced by the ventricular contraction may be facilitated by the decrease in pericardial pressures overlying the atrial surface [19]. The diastolic forward flow occurs when the tricuspid valve opens. The systolic peak is usually dominant and corresponds to the $\mathrm{X}^{\prime}$ descent of the right atrial pressure pulse. The diastolic forward flow velocity, which is the nondominant peak in normal patients, corresponds to the flow from the right atrium to the right ventricle through the opening of the tricuspid valve ( $\mathrm{Y}^{\prime}$ descent) in the right atrial pressure pulse. In the present study, the Df and $\mathrm{Sf}$ velocities were almost equal in patients with mild pulmonary hypertension $(25-35 \mathrm{mmHg})$, whereas the ratio was more than one (Df velocity $>$ Sf velocity) in patients with severe pulmonary hypertension. The former pattern would imply an increased right ventricular filling pressure in early diastole and a secondary increase in right atrial pressure, while the latter pattern indicates that right ventricular contractility is significantly diminished and early right ventricular failure would be present $[9,12]$.

The Doppler technique is noninvasive, accurate and easy to record in most patients. However, the present 
authors think that this method has some limitations, and various measures should be taken in order to minimize or avoid technical errors as follows. Firstly, extreme care must be taken in the presence of tachycardia or arrythmia as the venous pressure is unstable in these states [12]. Secondly, the patients with mild pulmonary hypertension $(25-35 \mathrm{mmHg})$ have variable ratios.

The development and advancement of echo machines during the past decade has been remarkable. The present authors propose that jugular venous flow velocity recording may possibly become one of the primary bedside methods for estimation of pulmonary hypertension in chronic obstructive pulmonary disease patients, so long as attention is paid to the limitations described above.

Acknowledgements. The authors appreciate the help of S. Yoshifuku (First Dept of Internal Medicine, Kagoshima University School of Medicine) and Y. Fukuoka (Second Dept of Internal Medicine, Kagoshima University School of Medicine) for their technical assistance and advice.

\section{References}

1. Weitzenblum E, Hirth C, Ducolone A, Mirhom R, Rasaholin-Jawahary J, Ehrhart M. Prognostic value of pulmonary artery pressure in chronic obstructive pulmonary disease. Thorax 1981; 36: 752-758

2. Swan HJC, Ganz W, Forrester J, Marcus H, Diamond $\mathrm{G}$, Chonette D. Catheterization of the heart in man with use of a flow-directed balloon-tipped catheter. $N$ Engl J Med 1970; 283: 447-451.

3. Kitabatake A, Inoue M, Asao M, et al. Non-invasive evaluation of pulmonary hypertension by a pulsed Doppler technique. Circulation 1983; 68: $302-309$.

4. Berger M, Haimowitz A, Van Tosh A, Berdoff RL, Goldberg E. Quantitative assessment of pulmonary hypertension in patients with tricuspid regurgitation using continuous wave Doppler ultrasound. $\mathrm{J}$ Am Coll Cadiol 1985; 6: 359-365.

5. Kilcoyne MM, Davis AL, Ferrer MI. A dynamic electrocardiographic concept useful in the diagnosis of cor pulmonale. Circulation 1970; 42: $903-924$.

6. Cohen HA, Baird MG, Rouleau JR, et al. Thallium
201 myocardial imaging in patients with pulmonary hypertension. Circulation 1976; 54: 790-795.

7. Berger HJ, Matthay RA, Loke J, Marshall RC, Gottschalk RC, Zaret BL. Assessment of cardiac performance with quantitative radionuclide angicardiography: right ventricular ejection fraction with reference to findings in chronic obstructive pulmonary disease. Am J Cardiol 1978; 41: 897-905.

8. Mammosser MO, Oswald T, Nyankiye E, Dickele MC, Grange D, Weitzenblum E. Non-invasive diagnosis of pulmonary hypertension in chronic obstructive pulmonary disease. Eur J Respir Dis 1987; 71: 419-429.

9. Ranganathan N, Sivaciyan V. Abnormalities in jugular venous flow velocity in pulmonary hypertension. Am J Cardiol 1989; 63: 719-724.

10. Weitzenblum E, Loiseau A, Hirth C, Mirhom R, Rasaholin-Jawahary J. Course of pulmonary hemodynamics in patients with chronic obstructive pulmonary disease. Chest 1979; 75: 656-662.

11. Kitabatake A, Jnoue M, Asao M, et al. Noninvasive evaluation of pulmonary hypertension by a pulsed Doppler technique. Circulation 1983; 68: 302-309.

12. Sivaciyan V, Ranganathan N. Transcutaneous Doppler jugular venous flow velocity recording. Circulation 1978; 57: $930-939$.

13. Laaban JP, Diebold B, Lafay M, Rockemaure J, Peronneau P. Detection of pulmonary hypertension by Doppler echocardiography of the inferior vena cava in chronic airflow obstruction. Thorax 1989; 44: 396-401.

14. Brawley RK, Oldham HN, Vasko JS, Henney RP, Morrow AG. Influence of right atrial pressure pulse on instantaneous vena caval blood flow. Am J Physiol 1966; 211: $347-353$.

15. Pinkerson AL, Luria MH, Freis ED. Effect of cardiac rhythm on vena caval blood flows. Am J Phisiol 1966; 210: $505-508$.

16. Brecher GA. Cardiac variations in venous return studied with a new bristle flowmeter. Am J Physiol 1954; 176: $423-430$.

17. Wexler L, Bergel DH, Gabe IT, Makin GS, Mills CJ. Velocity of blood flow in normal human venae cavae. Circ Res 1968; 23: 349-359.

18. Kalmanson D, Veyrat C, Chiche P. Atrial versus ventricular contribution in determining systolic venous return. A new approach to an old riddle. Cardiovasc Res 1971; 5: 293-302.

19. Holt JP, Rhode EA, Kines H. Pericardial and ventricular pressure. Circ Res 1960; 8: 1171-1181. 